Politica Obrera de cara a la lucha armada en Latinoamérica y sus diversas expresiones en los años sesenta

Sebastián F. Paris

Anuario No 34 / ISSN 1853-8835 / 2021

http://anuariodehistoria.unr.edu.ar/ojs/index.php/Anuario/index

\title{
Politica Obrera de cara a la lucha armada en Latinoamérica y sus diversas expresiones en los años sesenta ${ }^{1}$
}

\section{Politica Obrera facing the armed struggle in Latin America and its various expressions in the sixties}

\author{
SEBASTIÁN F. PARIS \\ Facultad de Filosofia y Letras, \\ Universidad de Buenos Aires, \\ sparis3850@gmail.com
}

RESUMEN

El presente artículo tiene por objeto indagar en la evolución de los posicionamientos que reflejó desde su prensa el movimiento de perfil trotskista Política Obrera (en adelante PO, antecesora del actual Partido Obrero) ante la lucha armada y su expresión en diversas experiencias de lucha en el continente. Pensamos que la Organización Latinoamericana de Solidaridad (OLAS), un organismo que se propuso centralizar y dirigir la lucha armada en América Latina, representó en PO el mayor acercamiento al paradigma guevarista. A su vez, creemos que la derrota de Ernersto "Che" Guevara en Bolivia, sumado a un mayor alineamiento del castrismo a Moscú y las experiencias de las jornadas del Cordobazo en Argentina, determinaron un alejamiento más marcado de dicho paradigma. Para ello, nos abocaremos al análisis de los posicionamientos y significados que otorgó al problema de la lucha armada en el continente.

Palabras clave: Política Obrera; trotskismo; guerrilla; lucha armada

ABSTRACT

This article aims to inquire into the positions that it reflected from his press the movement of trotskyist profile Politica Obrera (hereinafter PO, predecessor of the current Partido Obrero) facing the armed struggle and its expression in various experiences of struggle on the continent. We think that Organización Latinoamericana de Solidaridad (OLAS), an

\footnotetext{
1 Quiero agradecer las sugerencias recibidas por Juan L. Hernández a quien tengo mucha estima. Así como las lecturas de los colegas Matías Rubio y Natalia Casola. Las consideraciones vertidas corresponden a mi autoría.

Esta obra está sujeta a la Licencia Reconocimiento-NoComercial-Compartirlgual 4.0 Internacional de Creative Commons. http://creativecommons.org/licenses/by-nc-sa/4.0/ 
organism that proposed to centralize and direct the armed struggle in Latin America, represented in PO the closest approach to the Guevara's paradigm. In turn, we believe that Che's defeat in Bolivia, added to a greater alignment of castrismo to Moscow and the experiences of the Cordobazo days in Argentina, determined a marked departure from this paradigm. To do this, we will explore the birth and influences that this party received, the expectations in OLAS to, finally, focus on the positioning and meanings that it gave to the problem of armed struggle on the continent.

Keywords: Política Obrera; trotskyism; warfare ; armed struggle

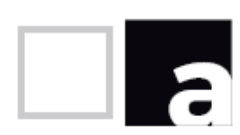

\section{Introducción}

La historiografia sobre las izquierdas argentinas cuenta con una larga tradición; sin embargo, la trayectoria de $\mathrm{PO}^{2}$ aún no ha sido abordada en profundidad por la academia. La centralidad que han tenido los estudios de las organizaciones armadas fue un factor que condicionó el estudio de la llamada "izquierda no armada", como lo fue PO. En su caso, la historiografia no ha avanzado más allá de las historias "oficiales" y el trotskismo anterior a PO (Tarcus, 1996; Amaral, 2005; Rojo, 2012-2013). Una de las obras pioneras en torno a su historia es el libro de Coggiola (1985) que en su obra general sobre la historia del trotskismo argentino, dedica su segundo tomo a enaltecer el papel de PO, sistematizar sus posiciones con relación a otras variantes de la izquierda y en especial a la tradición "morenista", con quien disputaba la construcción de una estrategia basada en la tradición teórica trotskista.

En sus inicios los trabajos sobre la historia del trotskismo vernáculo habian quedado en manos de los organismos oficiales partidarios (Magri, 1992; recientemente para PO Rath, 2015; en el caso del morenismo González, 1985). Auspiciosamente este déficit se ha ido a revirtiendo. Sin embargo, por el momento, no hemos podido acceder a documentos internos de la organización para el recorte temporal propuesto que nos alumbren los efectos de la "cuestión foquista" en PO.

\footnotetext{
2 El 24 de marzo de 1976, la dictadura cívico-militar argentina comandada por Jorge R. Videla ilegalizó a la organización, entre otras tantas. Tras el regreso de la democracia, sin embargo, su prohibición no fue levantada y tuvo que cambiar de nombre. Desde 1983 se denomina Partido Obrero. Desde el 2019 el partido está divido de facto por diferencias políticas, quedando así el Partido Obrero (oficial) y Partido Obrero (tendencia). Esta última es liderada por uno de sus fundadores, Jorge Altamira.
}

\section{anuario.}


Una forma de acercarnos al objeto de estudio será priorizar la voz

pública de PO a través de sus prensas y servirnos de las memorias que algunos militantes nos han proporcionado para subsanar la falta de acceso al registro interno. En ese sentido, el acercamiento es exploratorio y no definitivo. Nuestra hipótesis es que las críticas de $\mathrm{PO}$ al foquismo estuvieron mediadas por las imágenes que difundió Regis Debray en el continente. PO homologó todas las formas de lucha armada con el foquismo, que en realidad fue una táctica. Pensamos que en la discusión con el foquismo PO se sirvió de dos fuentes del trotskismo conosureño: los cuestionamientos del dirigente boliviano Guillermo Lora y los argumentos en la disputa que Nahuel Moreno mantuvo con Mario Santucho antes de la ruptura del Partido Revolucionario de los Trabajadores (PRT). Por último, el mayor acercamiento al paradigma foquista en $\mathrm{PO}$, lo constituyó su defensa sobre la Organización Latinoamericana de Solidaridad (OLAS). Sin embargo, tras la derrota del Che en Bolivia, el mayor alineamiento del castrismo a Moscú y las experiencias de las jornadas insurreccionalistas del Cordobazo en Argentina, determinarán un alejamiento definitivo. En la primera parte del trabajo se indagará la recepción de las lecturas del foco en Argentina a partir de la difusión de los escritos de Regis Debray. En una segunda parte el trabajo aborda el nacimiento de PO y la influencia que recibió por parte del POR-M y se estructura a partir de las conceptualizaciones en las que reparó dicho partido sobre la guerrilla en América Latina, tomando como casos la experiencia guatemalteca y boliviana. Por último, se explora el tratamiento que dio desde su órgano de prensa a la experiencia de la OLAS dirigida por el castrismo.

En términos generales, podriamos decir que la "teoría del foco", configurada por el Che Guevara y Regis Debray en la década del '60, tendió a darle más preponderancia a la técnica antes que a la teoría revolucionaria. Esto incluyó los manuales que leyeron los guerrilleros para saber cómo hacer la revolución y fueron desde balances de la experiencia revolucionaria argelina a manuales militares de Vo Nguyen Giap de la guerrilla indochina contra Francia, pasando por la resistencia israelita contra la ocupación británica en Israel, etc. La idea de aislarse en un foco rural era poder repeler un ataque desde el punto de vista militar y así iniciar un proceso tras el cual se formaría el ejército popular reclutando campesinos y acrecentar así a la guerrilla. En la guerra de guerrillas, si bien la lucha en las ciudades no es contraria, el Che las consideraba más bien subsidiarias, poniendo el énfasis en el foco rural. De este modo, lo programático quedaba en un segundo plano y el principal factor de unidad se concentraba en la lucha armada. Asimismo, el foquismo sostuvo que tiene que haber una unidad entre la lucha politica y la lucha militar, un mando unificado político-militar donde el líder era el guerrillero, quien puede tener formación política o no y donde es un combatiente más. E1 foquismo originalmente fue eminentemente rural, pero a fines de los `60 la teoría del foco va a recibir algunas críticas y se va a trasladar a un escenario urbano. En

\section{anuario.}


líneas generales, el foquismo consideró que "ya estaban dadas las condiciones para el levantamiento" y faltaba algo para que irrumpiera la revolución que generara esa crisis: dicha cuestión la debía contemplar el grupo armado.

\section{Las lecturas de la "teoria del foco" en la Argentina de los años ‘60}

Luego del triunfo de la revolución cubana, el principal cuerpo de ideas de la experiencia del ejército rebelde fueron los trabajos del Che, La guerra de guerrillas (1960), La guerra de guerrillas: ¿un método? (1963) y Pasajes de la guerra revolucionaria (1963), la que tuvo menos difusión hasta la muerte del Che. El primero, fue un manual político-militar que ofrecía una teoría del rol que debía desempeñar la guerrilla en las luchas políticas latinoamericanas, cuyos tres elementos centrales eran: 1) las fuerzas populares pueden ganar una guerra contra el ejército; 2) no siempre hay que esperar que se den todas las condiciones para la revolución, pues el foco insurreccional puede crearlas y 3) en América subdesarrollada, el terreno de la lucha armada debe ser fundamentalmente el campo. El segundo, postulaba que los campesinos eran una fuente central de la revolución y que la estrategia revolucionaria debe ser continental y coordinada entre los diferentes grupos guerrilleros del continente (Marchesi, 2019: 36-37).

En América Latina, la difusión del guevarismo se hizo a través de Debray, cobrando escasa difusión las obras del Che. El artículo de 1965, El Castrismo: la gran marcha de América Latina, fue traducido y editado como folleto para difundirse masivamente. En Argentina, en los ámbitos de la izquierda y la "nueva izquierda" de los ‘60, tendrá una gran divulgación. La revista Pasado y Presente $(P \text { y } P)^{3}-$ perteneciente al puñado de jóvenes intelectuales comunistas descontentos por la línea teórica y partidaria del PCA y colaboradores silenciosos con la lucha armada (Petra, 2017: 376) - introdujeron en Argentina la teoría foquista de Debray a partir de dicho artículo. En esa época, el francés trabajó para los cubanos recorriendo distintos países latinoamericanos, realizando balances de los diferentes derroteros de la lucha armada. La idea central fue que en los países subdesarrollados del continente la guerra de guerrillas debía iniciarse en el campo, para luego llegar a la ciudad. Los campesinos desempeñaban un rol central en el desarrollo del foco militar y las universidades se ofrecían como el principal "ejército de reserva" en las ciudades. Otro elemento es que cuestionará la construcción de una dirección política que sería reemplazada por la conducción militar. Así, la tendencia rural y la tendencia al militarismo fueron las ideas centrales del teórico francés (Debray, 1965: 122-158).

\footnotetext{
3 Ver PO N²-3, septiembre de 1964. p. 2. Alli constatamos que los cuadros de dirección leían Pasado y Presente.
} 
El filósofo argentino Néstor Kohan, desde una perspectiva guevarista, cuestionará las ideas vertidas por Debray. Señala que sus deficiencias pasaron por haber realizado una versión simplificada y manualizada de la experiencia cubana, transformada luego por él en "modelo" (Kohan, 2005: 173). El segundo ensayo, ¿Revolución en la revolución? (1967), alcanzó una mayor repercusión en América Latina. Desde alli canonizó al "foquismo" como estrategia de lucha armada para Latinoamérica, fustigando a los trotskistas que apoyaban la autodefensa armada y el insurreccionalismo, como ocurrió con los grupos MR-13 en Guatemala y el MIR de Hugo Blanco en Perú (Marchesi: 48). Allí, se reafirmaban elementos de 1965, pero ahora se profundizaba el sometimiento de la dirección política a la dirección guerrillera, las diferentes etapas de construcción de la guerrilla rural y los riegos de destruir "esa acumulación de fuerzas" a través del insurreccionalismo o la propaganda armada.

Debray habría construido una versión caricaturesca de la lucha armada que, con posteridad a la muerte del Che, le fue atribuida al ícono guerrillero (Kohan, 2005: 173-176). De este modo, mientras los libros del Che no se difundieron masivamente en América Latina, los libros de Debray sí lo hicieron. Entonces, tanto en Argentina como en Latinoamérica, las organizaciones de izquierda conocieron al foquismo por Debray, es decir, lo que se conoció fue de "segunda mano". No pretendemos plantear un antagonismo entre la dirección cubana y Debray, sino reponer que el modelo guerrillero cubano en Argentina fue estudiado a través del filósofo francés. En esta época, el guevarismo se convirtió en la corriente revolucionaria mayoritaria en Latinoamérica, en donde las corrientes reformistas, comunistas o nacionalistas que rompian con sus partidos, se incorporaban o simpatizaban con el guevarismo.

\section{La “cuestión guerrillera" en el nacimiento de PO}

A fines de 1963 nació PO, un nuevo partido de matriz trotskista. En su proceso de formación, la "teoría del foco" fue un detonante para su constitución. Este pequeño núcleo político, surgía luego de una ruptura con el Movimiento Izquierda Revolucionaria-Praxis (MIR-P), agrupación altamente intelectualizada que lideró el abogado, historiador y sociólogo marxista, Silvio Frondizi (Tarcus, 1996). En 1960 un grupo de militantes ${ }^{4}$ rompieron con MIR-P, reprochando el planteo de "movimiento de liberación nacional" sin base de clase y el abandono de la construcción de un partido obrero. Influenciado por la revolución cubana, para 1959 Frondizi sostuvo "que había quedado planteado en Argentina, construir una

\footnotetext{
4 Jorge Altamira, Claudio Perinetti, Marcelo Gramar, Julio Magri, Luis Torrens, Alberto Anaya y Mario
} Dávila. 
fuerza que agrupe a todos los elementos progresistas de los actuales partidos y que canalice las fuerzas obreras, particularmente la peronista" (Rath, 2015: 80). El grupo que luego crearía PO, fundó en diciembre de 1961 el Movimiento Izquierda Revolucionaria Argentina (MIRA), de corta existencia. E1 mismo se desintegraría en octubre de 1962 (Díaz, 2019: 4).

Hacia $1962^{5}$ se produciría una anteúltima ruptura en el MIRA, que daría lugar a Reagrupar, en la que la influencia del marxismo de la experiencia militante previa se armonizaba con la del foquismo en auge 6 . La mayoría de aquellos que rompian con esta trayectoria avanzaban insertándose en organizaciones político-militares, algunos serán fundadores de las Fuerzas Armadas Revolucionarias (Rot, 20032004: 141), otros irán al Frente Argentino de Liberación. Según el historiador Coggiola (2006), Altamira rompió con Reagrupar "sobre una base programática trotskista" y "por estar en contra del foco guerrillero del que dicho grupo aún se sentía atraído" (p. 208). Uno de sus miembros fundadores, en una especie de legitimación que justificaba la creación de un nuevo grupo trotskista, recuerda el último cisma que sobrevino en Reagrupar:

Una noche se dividieron (...) dos bandos: un bando se fue al foquismo y nosotros (...) a lo que es hoy el Partido Obrero [en aquél entonces PO]. Era el plenario de una efimera organización como Reagrupar. En octubre de 1963, siete militantes determinaron una ruptura final (...). Estábamos en el periodo de auge del maoísmo y de la revolución cubana. A raíz de una discusión de carácter estratégico, quedaron definidas dos tendencias: una maoista y pro-foquista, y la otra que hacia, por primera vez, un planteo basado en la tesis del trotskismo y en la necesidad de un trabajo estructural dentro del proletariado $y$ de sus organizaciones (Coggiola, 2006: 205-206).

Con este giro frentista y "populista" del dirigente del MIR-P todavía en órbita, la ruptura era retratada en el $\mathrm{N}^{\circ} 1$ de la revista Política Obrera, como ocasionada por su "naturaleza oportunista y liberal" que se encontraba "oculta". Una de las críticas centrales recaía en su renuncia a la tarea de construir el partido revolucionario, según su visión, huérfano todavía en Argentina y al hecho de entronizarse a la luz del influjo cubano, en un "rejunte de sectas bajo el slogan" de Frente de Liberación Nacional. Peyorativamente, PO consideraba que en ese "rejunte" el MIR-P habría entrado en la "disputa electoralera", abandonando así la tesis del partido, lo que los conducía a un tobogán a la burguesía nacional ( $P O \mathrm{~N}^{\circ} 1$, marzo de 1964, pp 1-5).

\footnotetext{
5 Como observa el historiador Javier Díaz (2017), desde 1955 hasta 1960 a través de su periódico Revolución, MIR-Praxis sostuvo la construcción de un partido obrero revolucionario, idea que se desechó un lustro después. Lucas Malaspina (2017) establece que el impacto de la revolución cubana produjo un cataclismo en el grupo, en torno a la reinterpretación del instrumento político y sobre su relación entre nacionalismo y socialismo, lo que en la Argentina de este tiempo significaba enlazarse con el peronismo.

${ }^{6}$ Por ejemplo, Ricardo Napurí - exiliado peruano ligado al grupo, también ex militante de MIR-Praxis se había entrevistado con el Che Guevara y regresado a Perú para participar de la guerrilla de Luis de la Puente Uceda; ulteriormente evolucionará hacia el trotskismo.
}

\section{anuario.}


De esta manera, el pequeño nucleamiento explicitaba la necesidad de la construcción de un partido obrero revolucionario. Proyecto que había abandonado MIR-P, pero que ellos continuarian. Simultáneamente, la emergencia de este grupo se dispondría a brindarle continuidad al leninismo-trotskismo como bandera de identidad política. No obstante, la organización en sus comienzos trató de definirse rápidamente, ya que su etapa previa estuvo signada por una fuerte contradicción y transición teórica-política, fruto del pasaje "populista" de Frondizi. En otras palabras, a pesar de que junto al líder del MIR-P, muchos de sus discípulos se habían aproximado a los clásicos del marxismo incluyendo al trotskismo, nunca se habian declarado como tales e inclusive se mostraban ajenos a los debates en el seno de la IV Internacional. Es entonces que, con el acercamiento y profundización a los escritos de Trotsky, el núcleo inicial irá tomando una identificación cada vez más vinculada al extinto líder bolchevique.

\section{“¿Foco insurreccional o partido revolucionario?”}

Entre 1963-1964 el periodista y creador de Prensa Latina, Jorge Masetti, dio los primeros pasos en Argentina para comenzar una guerrilla de tipo foquista con apoyo logístico, financiero y humano del Che. Luego de algunas reuniones en Cuba, Masetti decidió ponerse bajo su dirección como Comandante $2^{\circ}$ y fue así que a inicios de 1964 se dio curso, en la localidad salteña de Orán, a la primera operación del Ejército Guerrillero del Pueblo (EGP). El EGP formó parte de la estrategia cubana de impulsar focos guerrilleros en América Latina en los primeros años `60. Trágicamente, la operación fue abortada por la Gendarmería que redujo a algunos de sus integrantes y Masetti terminó desaparecido en el monte.

Es posible aseverar que en términos teóricos, PO concibió al foquismo como algo que se oponía a la estructura partidaria. Desde un patrón leninista, PO razonaba que en el partido se debía concentrar toda la experiencia histórica de la clase y, por este motivo, él mismo debía ser la vanguardia consciente que dirigiera el proceso revolucionario y moldeara la política y la estrategia militar a seguir. Esta posición no negaba el armamento parcial 7 o el entrenamiento militar que permitió en algunos de sus militantes. Así, su editorial neófita se distanciará de la estrategia del

\footnotetext{
7 Hemos advertido el armamento parcial de algunos militantes en esta época, ante las manifestaciones o actos relámpagos. En lo que fueron los aniversarios ante la muerte del Che, un militante de aquellos años como Claudio Katz (Agosto-2017) nos recordó que: "Yo entré el día que participé de una manifestación en el $3^{\circ}$ aniversario de la muerte del Che. Fui a este tipo de manifestaciones que eran de carácter clandestinas en el contexto de la dictadura [de Ongania]. Se juntaba un grupo, se repartían y tiraban algunos volantes y se lanzaban algunas bombas molotov. Venía la policía y nos escapábamos. Eran como actos clandestinos de acción relámpagos".
} 
foco insurreccional apoyándose en el paradigma leninista, sugiriendo que el mismo podría servir como un punto de llegada en el asalto al poder proletario y no como su punto de partida. Puede conjeturarse que el partido no negaba entonces la violencia política por principio, sino los medios y el programa al que apuntaba la misma. El foco reflejaba, en sus palabras, la "concepción técnica" de la dirección revolucionaria, siendo antagónico a la concepción del partido. Para PO había que privilegiar la inserción en el seno de la clase obrera como labor central, necesaria y que antecediera la toma del poder, para concretarla en insurrección armada. El partido, en su visión, no era un mero aparato a cargo de la técnica insurreccional, sino un orientador, un organizador, un factor consciente que educado y educando en una ideología revolucionaria cree primero e instrumente después las condiciones de la insurrección armada.

Es necesario aclarar la naturaleza distinta de foco y partido. El foco, frecuente y lógicamente asociado como foco insurreccional, expresa la concepción "técnica" de una dirección revolucionaria (...). El antagonismo con la concepción del partido es evidente. Para el leninismo "la insurrección no debe apoyarse en una conspiración, en un partido, sino en la clase más avanzada". ¿Pero cómo puede una vanguardia lanzar la táctica de la insurrección apoyándose en la clase más avanzada, sino ha ganado la dirección de esa clase (...) Enfocado así, el proceso de (...) la toma del poder, culmina con la insurrección, que es el grado más elevado del antagonismo de clase y que expresa el alto nivel alcanzado (...), pero es precedido por todo un periodo lucha, utilizando todas las formas y medios existentes (...). [Por todo esto], la tarea (...) por delante es la construcción del partido revolucionario. (...) (PO $N^{\circ} 1$, marzo de 1964, pp. 5-8)8.

PO se definió como una organización insurreccionalista dado que su apuesta ponía el eje en la conquista de la dirección de la clase obrera con la perspectiva de una insurrección de masas. Al mismo tiempo, polemizando contra el argumento que se lanzaba a favor de "esta tesis (consistente) en el rol impulsor y excitador que la presencia del foco crea en la conciencia de las masas oprimidas", PO señaló que el mismo sustituía y negaba la naturaleza del partido y —en la medida que se concibe como independiente de toda organización partidaria- llegaba a implicar la negación del proletariado como única clase revolucionaria. Puede notarse tempranamente, que la organización homologó el foco con lucha armada, afirmando que el ejemplo que inspiró a las distintas variantes del foco fue la revolución cubana, en donde "se ha tomado (...) la lucha armada en la sierra y se lo ha aislado del conjunto". En este sentido, lo que se impugnaba al foco no era la violencia sino el hecho de que rehuía del trabajo político en las filas de la clase obrera, desentendiéndose de la cuestión programática y de dirección.

\section{La estela del POR Masas (POR-M) en PO sobre la "cuestión foquista"}

\footnotetext{
8 El resaltado nos pertenece. Subrayado en el original.
}

\section{anuario.}


Podria conjeturarse que la falta de una experiencia teórica y militante previa anclada al campo trotskista predispuso a la incipiente PO a nutrirse y asimilar argumentos y posiciones político-teóricas de otras corrientes trotskistas -incluso de su adversario morenista- para subsanar dicho déficit. Creemos que la influencia del POR-M boliviano, de extracción trotskista y presidida por el dirigente Guillermo Lora, es un caso que se corresponde a nuestra premisa. Así, el POR-M permeó a la joven organización ${ }^{9}$ pero no en todos los órdenes ${ }^{10}$. La producción de Lora fue leída por los militantes argentinos, sirviéndose de sus críticas al foquismo pero transmutándolas como críticas a la "lucha armada" en general. En contraste, Lora esbozó controversias en un sentido político-metodológico, pues consideraba necesaria la guerrilla en la futura realidad política boliviana. A partir del relevamiento de prensa para este recorte temporal, pudimos advertir que fue frecuente en PO la reproducción de algunos artículos del periódico Masas e incluso la venta de algunas de sus obras ${ }^{11}$. Aunque no sólo en estos ámbitos de visibilización pública se expresó dicho ascendente12. Para la formación teórica y programática trotskista de los militantes se valieron de folletos del dirigente altiplánico. En la memoria de un militante de aquella época, dicha influencia del POR-M nos fue reconocida:

Yo me acuerdo del seguimiento muy estrecho de todas las noticias que llegaban de Bolivia. Tengo presente que se hacian algunos cursos de formación política al interior del PO con un material sobre la Revolución permanente que habia elaborado Lora. Un pequeño folleto donde él rastreaba los antecedentes de la revolución permanente en Marx y luego lo tomaba en Trotsky analizando el proceso revolucionario de 1905 en Rusia y, por supuesto, en 1917. Para mí, eso era importante ${ }^{13}$.

En otro testimonio, y determinando un peso aún mayor, un militante contemporáneo que se unió en los '70 ha ido más lejos considerando que "PO llegó

\footnotetext{
9 Esa influencia no se mantuvo inalterable. En la década del `80 PO rompería lazos con el POR-M.

10 Mientras PO no disputó políticamente en el campo electoral hasta 1983, POR-M en cambio sí lo hizo. Esta es sólo una de las diferencias.

11 Por ejemplo, Revalorización del método de las guerrillas. Masas (1968) y La revolución Permanente (folleto elaborado por el POR-M). Ver " $1^{\circ}$ de mayo apostar más que nunca al derrocamiento del capitalismo mundial y de la burocracia contrarrevolucionaria”. En $P O \mathrm{~N}^{\circ} 50$. Boletín Quincenal. Año III. (21/4/1969). p. 32

12 También se pueden encontrar conceptos que el dirigente boliviano utilizó para analizar e intervenir en la realidad altiplánica, como por ejemplo la caracterización del MNR como un "cadáver insepulto", de las cuales PO trasladaria para interpretar al peronismo.

13 Entrevista del autor a J.H. (febrero- 2020). Si bien no corresponde a nuestro recorte temporal, el entrevistado señaló que "la cercanía era mucha y era como que los militantes teníamos una imagen muy idealizada del POR-M, llegaba hasta ese punto la cercanía politica. De hecho yo recuerdo algunos afiches que se hicieron cuando se realizó el Congreso de fundación de la Unión de Juventudes por el Socialismo (UJS) en 1972 que tenían clara influencia de los mineros bolivianos. Eran afiches con mineros bolivianos con la cuestión de las milicias obreras y demás".
} 
al trotskismo por Lora y el POR-M"14. Notamos que las memorias en torno a la permeabilidad del POR-M en el PO son dispares.

En 1966, el POR-M había sido asesorado por Allende y participó en la conferencia Tricontinental en La Habana como parte de la delegación CODEP ${ }^{15}$. Lora y su frente habian sido excluidos. De este modo, reponer en las posiciones de Lora implica tener presente el conocimiento más cercano en comparación a los de PO, que se basó en documentos de segunda mano para elaborar sus definiciones (como los periódicos Marcha y Época, ambos uruguayos).

En relación al POR boliviano, tanto el POR Masas (POR-M) y el POR Combate (PORC), habian defendido entusiastamente la revolución cubana, aunque el POR-C iba un poco más allá, apoyando a la dirección fidelista. En 1964 en el marco del golpe del Gral. Barrientos, el POR-M defendió la permanencia de las milicias obreras y campesinas creadas en la revolución del `52. El POR-M fue favorable a la tesis de que simultáneamente a la puesta en acción de la organización de las milicias debía asimilarse la lucha guerrillera. O sea, no la rechazaba por principio sino que la entendía a la manera leninista, como un recurso más de lucha, subordinado a la estrategia insurreccional y bajo la dirección del partido de la clase obrera. Para Lora, la estrategia insurreccional no obstaculizaba la formación de organismos guerrilleros, pero éstos debían ser siempre subsidiarios de la estrategia insurreccional partidaria ${ }^{16}$.

Los nudos críticos más sustanciales de Lora al foco se encuentran en el libro Revolución y foquismo. Balance de la discusión sobre la desviación "guerrillerista", que reúne artículos escritos entre 1963 y 1972, periodo en el cual el foquismo hallaba mayor arraigo en las direcciones revolucionarias. Allí, acometió la tarea de diferenciar guerrilla y foco. La primera sería una actividad propia de las masas explotadas librando una guerra informal contra el ejército y el Estado; en este sentido, la guerrilla sería el brazo armado de los explotados. El segundo se organizaría y actuaría, en su concepción, "al margen de las masas, buscándolas suplantar y creyendo que empuñando el fusil reemplazarian al partido político y resolverían el problema de la conciencia de clase”. Esta última crítica será retomada literalmente por PO para elaborar su propia representación sobre la cuestión guerrillera. Lo que habría hecho el foquismo según Lora fue trastocar la táctica por la estrategia, por lo que sería equívoco reducir la violencia revolucionaria a una

\footnotetext{
14 Entrevista del autor a A. Guerrero (2018 y 2020). El hecho de que Guerrero haya militado 5 años en el POR-M en Bolivia entre 1983-88, pudo haberle creado una imagen más fuerte de que la que comúnmente se tiene constancia.

15 Desde Bolivia, acudieron dos delegaciones: la encabezada por el PCB llamada FLIN, y la delegación del CODEP encabezada por el POR (unificado), un sector del MNR, Lidia Gueiler (del PRIN lechinista) y los grupos proto-maoístas que luego conformarán el PCMLB. Los cubanos, actuaron de forma tal que solamente reconocieron a los grupos que estaban dirigidos por el PCB, puesto que se erigía "representante legítimo de la clase obrera y el campesinado".

16 Prólogo de Grenat, Stella. pp. 18-19. En Lora, Guillermo. Revolución y foquismo. Balance de la discusión sobre la desviación "guerrillerista”. Buenos Aires, Ed. RyR. 2011. p. 187.
}

\section{anuario.}


cierta forma de lucha armada (2011: 60-78). Se evidencia aquí como

el lorismo identificó al foquismo como una táctica, entre otras, de la lucha armada. Si bien PO estuvo influenciado por el POR-M, no cabría adjudicar que entendió y compartió los argumentos del dirigente boliviano, ya que Lora diferenció al foquismo de lucha armada.

Otro afluente teórico-político de $\mathrm{PO}$ en el que se apoyará para interpretar al foquismo, fue la corriente "morenista"17 en Argentina. Si bien no explícitamente asumido, PO siguió los debates e incluso utilizó algunos de los argumentos de Palabra Obrera y luego Partido Revolucionario de los Trabajadores - La Verdad en torno a su distancia al foco (Díaz, p. 20). Explorando el paradigma de la revolución cubana y sus efectos en Palabra Obrera, Mangiantini ha puesto de relieve el envío de militantes a realizar entrenamiento a la isla, pasando por álgidos debates internos, hasta las rupturas de Ángel Bengochea y Daniel Pereyra (2014a: 40). Creemos que PO tomó elementos de la discusión de Moreno con Santucho respecto al "foco", antes de la ruptura del PRT en 1968.

\section{PO y sus lecturas sobre las guerrillas latinoamericanas. Las experiencias guatemalteca y boliviana}

PO siempre que exploró el carácter político de los grupos guerrilleros miró sus aspectos programáticos. Si bien uno de los mayores acercamientos de PO al foquismo fue el apoyo al Movimiento Revolucionario 13 de Noviembre (MR-13) guatemalteco, pensamos que un apoyo más orgánico fue la OLAS. Empero, esos acercamientos ya eran palpables a finales de 1965 y 1966.

En el caso de Guatemala, a mediados de 1963, por necesidades logísticas los guerrilleros del MR-13, liderado por el capitán Marco Yon Sosa, se acercaron a los trotskistas posadistas guatemaltecos y mexicanos. Estos proporcionaron ayuda y se introdujeron a la guerrilla. A partir de esta influencia, en 1964 el MR-13 adoptó un programa socialista ${ }^{18}$. Al cumplirse el $5^{\circ}$ aniversario del MR-13, PO reprodujo sus declaraciones ( $P O \mathrm{~N}^{\circ}$ 5, enero-febrero de 1966, pp. 28-29) y lo apoyó valuando que era la dirección de masas más consciente y avanzada de Latinoamérica por sus ligazones efectivas con las masas (PO N 3, agosto-sep. de 1965). En 1968 PO percibió como positiva la ruptura de las Fuerzas Armadas Rebeldes ${ }^{19}$, de espíritu netamente foquista, con el Partido Guatemalteco del Trabajo, que pretendía dirigir

\footnotetext{
17 En especial la obra de Nahuel Moreno: Dos métodos frente a la revolución latinoamericana (1964).

18 Ver Declaración de la Sierra de las Minas.

19 Las F.A.R. surgen en 1962 a raíz de un acuerdo entre el MR-13 y el PGT en razón del cual este último aportaría medios económicos y sus propios cuadros militares, apareciendo como Destacamento 20-Octubre y no asumiría totalmente el compromiso politico. En Pereyra. D, Del Moncada a Chiapas. Historia de la lucha armada en América Latina. p. 244.
}

\section{anuario.}


la guerilla desde las ciudades, negándose a incorporar sus cuadros militares y desconociendo el liderazgo de César Montes tras la muerte de Turcios Lima ( $P O \mathrm{~N}^{\circ} 28,25 / 3 / 1968$, pp. 18-27; $P O \mathrm{~N}^{\circ} 26,15 / 2 / 1968$, pp. 23-25). Desde la perspectiva de $\mathrm{PO}$, las FAR no sólo rechazaban la teoría del "tránsito pacífico" al socialismo, sino que luchaban por imponerle un carácter clasista a la lucha armada y no se limitaban a plantear el desarrollo del foco armado $\left(P O \mathrm{~N}^{\circ} 27,7 / 3 / 1968\right.$, pp. 18-22). Allí, PO resaltaba el acercamiento entre las FAR y el MR-13 que se había definido por un programa socialista, puesto que

Ni las FAR ni el MR-13 intentan hacer foquismo, copiando (...) abstractamente a Cuba (...), sino organizar a las propias masas en el terreno y en el curso de la guerra civil. La guerrilla organiza comités campesinos, los que hacen las veces de bases revolucionarias para la información, el abastecimiento y el reclutamiento en toda esta primera etapa de lucha (op. cit., pp. 20-21).

En su mirada, PO estimaba oportuno que tanto el MR-13 como las FAR hayan apelado a la propaganda armada entendida como un atributo que se oponía al foquismo. PO, pensaba que era "denigrada por los foquistas (Debray, que repudia la propaganda armada porque se mueve en el terreno de la lucha armada en abstracto)" (ibídem. p. 21). Allí, PO aludía a Montes de las FAR quien le atribuía a la propaganda armada un papel clave en la tracción campesina (pequeños propietarios y medieros) a la revolución. En verdad, la cuestión de la propaganda armada estuvo presente en las premisas metodológicas de la lucha guerrillera del Che tanto en sus escritos de 1960, como de 1967 en su mensaje a la Tricontinental20. Puede notarse aquí que PO leyó al foco a través de las teorizaciones del filósofo francés, que en 1967 había sugerido desechar la propaganda armada en el continente porque destruiría "esa acumulación de fuerzas" que generaría el foco.

A su vez, PO defendió los atentados guerrilleros de ajusticiamiento en los centros urbanos, amparados por la "bárbara matanza cotidiana de militantes y ciudadanos por la policía, ejército y grupos de derecha21. Tenemos la impresión que PO apoyó al MR-13 no por su politica claramente guerrillerista, sino por su acercamiento - a

20 La propaganda más efectiva es la que se hará desde dentro de la zona guerrillera. Se dará preferencia a la difusión de las ideas para los naturales de la zona, explicando teóricamente el hecho, para ellos conocido, de la insurrección. En esta sección habrá también periódicos campesinos, el órgano general de todas las fuerzas guerrilleras y boletines y proclamas, además del radio. (...) Por radio se explicarán todos los problemas, la forma de defenderse de los ataques aéreos, por dónde están las fuerzas enemigas, citando nombres familiares (...) La radio es un elemento de extraordinaria importancia. En los momentos en que la fiebre bélica está (...) palpitante en [c/u] de los miembros de una región o de un país, la palabra inspiradora, (...) aumenta esa misma fiebre y la impone en cada uno de los futuros combatientes. Explica, enseña, (...) determina en amigos y enemigos sus posiciones futuras. Che Guevara, Guerra de Guerrillas, 1960; "Nuestra misión, en la primera hora, es sobrevivir, después actuará el ejemplo perenne de la guerrilla realizando la propaganda armada en la acepción vietnamita de la frase, vale decir, la propaganda de los tiros, de los combates que se ganan o se pierden, pero se dan, contra los enemigos". En Mensaje del Che Guevara a los pueblos del mundo a través de la Tricontinental. Ernesto Guevara. Abril 1967.

21 Se refiere al surgimiento de la organización parapolicial y derechista Mano Blanca. "Guatemala: ruptura...”. Cf. p. 21 
través del posadismo- al trotskismo y por los blancos de ataque del que fue objeto el MR-13 por Debray ${ }^{22}$. De hecho, reprodujo la entrevista a un miembro del MR-13, en donde éste aseguraba que la contribución del posadismo fue "acortar el camino al programa socialista" ( $P O \mathrm{~N}^{\circ} 28,25 / 3 / 1968$, p. 32).

En el proceso boliviano, la primera alusión sobre la guerrilla de Ñancahuazú data de julio de 1967. Algunas posiciones que hizo públicas el POR-M, coincidentemente, PO las tomó como propias para elaborar una definición. Al enterarse de la guerrilla, el POR-M desde la clandestinidad de los campos de concentración selváticos del barrentismo, prestó un decidido apoyo. En su periódico Masas explicaba que

1. El movimiento guerrillero no resuelve por sí sólo el problema número uno del proceso revolucionario (...): el problema de la dirección, como tampoco puede colocarse al margen de la situación politica del país (...). 2. En este momento de definiciones, el POR dice públicamente que se solidariza y apoyaba al movimiento guerrillero (...). Se asume esta actitud sin previamente considerar su fortaleza o debilidad, sus virtudes o defectos (...). Los guerrilleros, pese a (...) las limitaciones (...), son parte de la avanzada armada del pueblo (...) Nuestro homenaje de admiración al valor demostrado por los guerrilleros en su titánica lucha contra el gorilismo y las huestes yanquis (Lora, 2011: 184-185).

Puede notarse que el POR-M no fue refractario a la lucha guerrillera. Cuestionando la validez como "única forma de lucha", solo en determinadas condiciones y temporalmente, podría llegar a convertirse en el método de lucha preeminente.

Al enterarse de la guerrilla, PO compartió una declaración que desde la clandestinidad escribió el dirigente Hugo Moscoso quien, con Lora, formaba parte de la Sección Boliviana de la IV Internacional. En los años `60, el POR-C, bajo la égida de la IV Internacional, había asumido la estrategia foquista del guevarismo y promovido el ingreso de sus militantes al ELN boliviano. En esa línea, el comunicado de las dos fracciones, estimaba que el movimiento guerrillero no era una trasposición mecánica de la experiencia cubana. En Bolivia, según el comunicado, los guerrilleros habrian surgido como "culminación natural" de los procesos politicos internos. Por ello, era imperiosa la tarea de los revolucionarios de agudizar esta lucha, defenderla y extenderla. En efecto, PO apoyó las acciones de los combatientes de Ñancahuazú, pero siempre en la línea del manifiesto de que las ciudades se volvieran sus bases de apoyo. La mayor ayuda que podía bridársele, continuaba el comunicado, era hacer avanzar las luchas de las masas urbanas, de mineros, obreros y campesinos por sus propias reivindicaciones y preparar comités clandestinos y milicias armadas, debiendo reaparecer en los sindicatos. Así, las masas bolivianas, debian partir del nivel de experiencias que las habian llevado a

22 En su artículo de 1967 afirma que: "trotskismo y reformismo se dan la mano para condenar la guerra de guerrillas, frenarla o sabotearla”. Citado en Marchesi. p. 48-49. 
sus conquistas más recientes (PO $\mathrm{N}^{\circ} 18,19 / 7 / 1967$, pp. 4-5). El manifiesto reclamaba a la guerrillera tomar como base la experiencia de lucha de los mineros que habían sido claves en la revolución de 1952. En ese sentido, se exigia una mayor atención a la especificidad nacional, asunto que el foquismo habría subestimado, al tiempo que se apoyaba la guerrillera presente.

Cuando se conocieron las noticias de las ejecuciones de combatientes y la del propio Che, PO reflejó desde su tapa de prensa en noviembre de 1967, Viva el Che Guevara. Ante su muerte, la comandancia del ELN había quedado en manos del "Inti" Peredo23. Alli se repudiaban los homenajes, hechos por los PP.CC. latinoamericanos y la URSS a su figura ya que, desde el punto de vista de la organización, la derrota del ícono de la guerrilla latinoamericana había sido por "la traición del PCB". PO se refirió tanto a la OLAS como a la guerrilla puntualizando que era necesario discutir el balance politico que dejaba la experiencia boliviana, para "encarar conscientemente la reorganización de la lucha revolucionaria y guerrillera en el Altiplano". En tal sentido, la dirección de la OLAS no debía reducir lo ocurrido a un inventario de deficiencias técnicas $\left(P O \mathrm{~N}^{\circ} 21,2 / 11 / 1967\right.$, p. 2). Su apoyo no la dejaba exenta de reprochar que en ese embarque guerrillero, si estaba desplazada "la perspectiva de una táctica que no pise firme en la tarea de construir el partido revolucionario, de reagrupar a la vanguardia minera y de atraer a la vanguardia de los campesinos más pobres y más explotados" se caería en vano, por lo que era clave reformular la política estratégica (ibídem).

En 1968, Lora editó Revalorización del método de las guerrillas, momento en el cual la estrategia del foco se acrecentaba tras la muerte del Che. Desprovisto de una mirada denigratoria, el histórico dirigente del POR-M, exhortaba a asimilar críticamente "la rica experiencia del fracaso de Ñancahuazú". La lucha armada sería central para la revolución boliviana y, por ello, el método de la lucha de las guerrillas se incorporaría definitivamente al arsenal revolucionario, señalaba Lora ${ }^{24}$.

En noviembre, cuando la guerrilla se encontraba prácticamente desarticulada y los pocos sobrevivientes intentaban cruzar a Chile, PO reprodujo nuevamente un artículo del POR-M donde se exigía una "recapacitación" sobre el balance que dejaba la estrategia foquista. Igualmente, el artículo reclamaba respaldarla, fortalecerla, sacarla del aislamiento y ligarla con el movimiento de masas de las ciudades. Respecto a la cuestión campesina, creemos que PO subestimaba los significativos lazos políticos-clientelares que había enhebrado Barrientos 25 — cuyo corolario fue el pacto militar campesino (PMC) - con el campesinado, estableciéndo que "no había ninguna razón" para que los campesinos pudieran apoyar al régimen militar. Para el POR-M, las masas campesinas "estaban contra la dictadura y

\footnotetext{
23 Álvaro Peredo Leigue, fue miembro de la Juventud del PCB de La Paz. Ya desde 1963 venía prestando ayuda a la guerrilla foquista, como lo fue en el caso del EGP y el caso peruano.

${ }^{24}$ Lora, G. Revalorización del método de las guerrillas (1968). En Revolución y foquismo... p. 182

25 Barrientos hablaba fluidamente el quechua.
}

\section{anuario.}


decididamente a favor de la guerrilla", pero todavía eran incapaces de

movilizarse. Para ello era necesario hacer avanzar las luchas campesinas $\left(P O \mathrm{~N}^{\circ} 22\right.$, 23/11/1967, pp. 30-34). El PMC sería central en la estrategia barrentista de desactivar el foco rural, no sólo por el escaso apoyo que tuvo el ELN sino también porque los sectores rurales bolivianos actuaron -como observa el historiador Rodriguez Ostria- como los ojos del Estado delatando el paso guerrillero y retaceando su apoyo en alimentos y combate (2018: 80). En el mes posterior, a partir de un reportaje del periódico norteamericano trotskista The Militant se reforzaba la visión de la traición del $\mathrm{PCB}^{26}$ junto a los "errores de la guerrilla" por haber dejado incorporar elementos "lumpenproletariat", gente no probada e incapaz de soportar pruebas de una prolongada lucha guerrillera $\left(P O \mathrm{~N}^{\circ} 23,14 / 12 / 67\right.$, pp. 23-24). A mediados del año 1968, cuando Barrientos volcaba la situación políticomilitar en su favor haciendo perder capacidad de acción y fuerza al foco, se vaticinaba que en Bolivia "no sólo los de arriba ya no pueden seguir como hasta ahora sino que los de abajo ya hace mucho que no quieren vivir como vivian y viven". De este modo, se consideraba que el gran problema, seguía siendo la ausencia de una dirección revolucionaria. En consonancia con los análisis que Lora promoviera en 1963 en Las guerrillas: la concepción marxista contra el golpismo aventurero $^{27}$, se apuntaba a que la guerrilla debía ser parte de la insurrección.

Una vez conocido el manifiesto de Inti, PO lo reprodujo en su prensa para cuestionar el relanzamiento del foco guerrillero con aval cubano. Allí, Inti concluía que no se buscaba organizar ni ser el "brazo armado" de un partido politico, porque el foquismo en transcurso de reiniciación sería capaz vencer al ejército, al tiempo de "crear" a los dirigentes. Sin embargo, decía que la lucha de las ciudades debía coadyuvar a la acción guerrillera pero que, fiel al arquetipo guevarista y las resoluciones de la OLAS, esta no podría dirigir la guerrilla, sino el grupo armado de vanguardia del ELN (PO N $\mathrm{N}^{\circ} 34,5 / 8 / 1968$, pp. 2-3). En este sentido, PO entendió que la debilidad de la concepción foquista radicaba en creer "que la reorganización política de las fuerzas bolivianas revolucionarias iba a ser el subproducto de la lucha armada pura". El foco, en la visión de PO, no crearía al partido, sólo podría sobrevivir y desarrollarse como parte del programa del partido revolucionario. Así, se asimilaban las concepciones teóricas del POR-M en torno a las críticas al paradigma guevarista.

En el $1^{\circ}$ aniversario de la muerte del Che se balanceaba que la perspectiva del movimiento de masas y su futuro no estaban en la "construcción del foco aislado,

26 Estudios actuales ha repuesto el papel del PCB. R. Ostria, por ejemplo, sostiene la poca flexibilidad política que tuvo el Che ante las peticiones de Mario Monge. Sin embargo, no puede negarse la colaboración que prestó el PCB ante la persecución por las tropas de elite norteamericanas y los rangers bolivianos, después de la muerte del Che. Así, en 1968 a través de la cooperación de militantes del PCB, el Inti Peredo organizó la salida hasta el poblado de Sabaya, en el departamento de Oruro, cerca de la frontera con Chile, donde los esperaba Salvador Allende.

27 Disponible en: https://www.marxists.org/espanol/lora/1963/iun00.htm. Consultado: 26-9-2020. 
esclarecido y armado", sino en la constitución del partido revolucionario de la vanguardia obrera. Para la organización argentina, Fidel y el Che habian opuesto el foco al partido, pero entendiendo como tal partido a la burocracia de los PP.CC. En su cosmovisión, PO creía necesario la intervención a partir de la experiencia política cotidiana de la vanguardia. Por el contrario, el guerrillerismo creía que tenía el poder de suprimir dicha experiencia y fundar las condiciones subjetivas de la insurrección. Esto traería como consecuencia, para el reducido grupo de trotskistas argentinos, el aislamiento descomunal de los focos guerrilleros y es lo que explicaba la derrota del Che (PO N $37,30 / 9 / 1968$, pp. 2-3). Paralelamente, a pesar de la aversión castrista al burocratismo stalinista, fue un error intentar pactar una y otra vez con tales burocracias para desarrollar la lucha armada, así lo demostraba Bolivia, sentenciaba PO. Ya en el $2^{\circ}$ aniversario de la muerte del Che, se balanceaba que la derrota en Bolivia se debió tanto a la "insuficiente compresión histórica del Che y de la dirección castrista" como de los acuerdos con los stalinistas en la Tricontinental que devinieron en "traición", quedando el Che aislado y sin contacto con las masas. Seguidamente, se afirmaba que la OLAS se habría hundido irremisiblemente con la extinción de la guerrilla en Bolivia, ya que su desconfianza en la clase obrera, su excesiva seguridad en la "fuerza pura de un aparato" y "su acción ciega", se constituyeron en la raíz del fracaso foquista ( $P O \mathrm{~N}^{\circ} 59,20 / 10 / 1969$, pp. 6-7).

En suma, la falta de conexión entre las acciones bélicas de los guerrilleros y las movilizaciones masivas, fueron uno de los aspectos más débiles del movimiento revolucionario. Fue la falta de vinculación entre el partido de la clase obrera y Ñancahuazú. Ponderando también la virtud del enemigo en la represión, es decir, de las FF.AA. barrentistas, la influencia norteamericana y el apoyo de los gobiernos conosureños a la lucha antiguerrillera, Lora llamaba a pensar la cuestión del Comando Único de las fuerzas revolucionarias. Esa función debía cumplirla la OLAS, superando, según él, su sectarismo; había que reestructurarla ajustándose al centralismo democrático. Otro de los aspectos que Lora criticará a Debray fue el hecho de descartar la autodefensa armada —el armamento de la clase obrera alrededor de los sindicatos que apuntalen la acción directa incluyendo a las milicias obrero-campesinas - para Bolivia y Latinoamérica. Este método de lucha habria triunfado en la revolución del ` 52 y era una herramienta central en la concepción de Lora.

\section{La delimitación con el PRT (EC) y PRT (LV) sobre la lucha armada}

En 1968 PO disentía con el PRT recientemente escindido, acerca de que en Argentina se estaba a las puertas de una "guerra civil revolucionaria" y lo acusaba de "terrorista", aunque no descartaba que la estrategia para la toma del poder por parte de la clase obrera siguiera pasando por el camino de la lucha armada. Sin

\section{anuario.}


embargo en su mirada, en Argentina todavía no se había llegado a un

nivel de la lucha de clases que refrendara el armamento de una fracción de la clase obrera $\left(P O \mathrm{~N}^{\circ} 24,4 / 1 / 1968\right.$, p. 17), aunque había que enseñar el manejo de las armas a los cuadros partidarios; esa era una forma "de ir rompiendo las vallas entre el hombre y el fusil" (ibídem.).

No estamos por la lucha armada en abstracto sino por la insurrección, el levantamiento armado, el armamento de las masas (...) El PRT señala que ha sonado el momento de la lucha armada sin hacer planteo insurreccional (...) su posición se reduce al terrorismo (...) o al foquismo planteado por el Che o Debray, que es el único planteo insurreccional conocido hoy en América Latina (...) (ibídem).

PO siguió otorgándoles un mismo razonamiento tanto al PRT-EC y el PRT-LV respecto a la lucha armada, calificándolas de "neoputchistas" y "subjetivistas incorregibles". En el siguiente apartado, puede advertirse la reapropiación lorista de PO sobre la negativa a "la importación del grupo guerrillero" en las distintas realidades nacionales.

Cuando la clase intenta dar una salida frente al derrotismo (...) los putchistas la califican de aventurera, ¿qué se creen? ¿Que los activistas están esperando sus mesiánicos "focos" (...) para darse una actividad de clase, antidictatorial? (...) es una (...) aventura importar métodos armados traidos por pequeñoburgueses y (...) como una extensión de la lucha puramente sindical (PO $N^{\circ} 29,15 / 4 / 1968, p p .8$ 10).

La adhesión del PRT-EC a la línea de la lucha armada, a través de un foco selecto y disciplinado, obedecía en PO "al paso del "putchismo" a la "política" que intentaba hacer socialismo revolucionario sin proletariado y sin partido". Para dicho partido, las "huellas morenistas" en el PRT-EC seguían todavía vigentes en la cuestión de la lucha armada, al punto que a ambas fracciones le atribuía una idéntica concepción.

La función de la lucha armada (...) nunca pasó de ser en ellos [Moreno] un arma de propaganda, como medio de ponerse a la vanguardia de la $\left[1^{\circ}\right.$ Conferencia de la OLAS, en forma oportunista. La concepción armada del PRT unificado, y luego [PRT-EC], consistió en una concepción sobre la insurrección, y de una concepción sobre la lucha armada como extensión y apéndice de la actual lucha sindical. En una palabra, "el reformismo y los fusiles" (PO N³2, 1/7/1968, pp. 30-31).

Influenciada en 1968 por las luchas insurreccionales que desplegaban los estudiantes franceses con la dirección de la Juventud Comunista Revolucionaria (JCR), dirigidas por el SU de la IV Internacional, PO agitaba planteos tales como los de formar comités de acción obreros-estudiantiles y ocupaciones de fábricas con rehenes $\left(P O \mathrm{~N}^{\circ} 31,10 / 6 / 1968\right.$, pp. 1-32). Tras el paro de la CGT-A el 28 de junio y en los aires fuertemente represivos de la dictadura de Ongania, planteó la creación de una red de comités barriales que combinaran su funcionamiento clandestino con 
otro más abierto para organizar la resistencia. El movimiento popular y sus demandas triunfarian sólo si podía voltear al gobierno a través de la insurrección. Por ello, "el primer paso son los comités de resistencia por fábrica y por zona, el frente obrero-estudiantil en la línea de los acontecimientos franceses" $\left(P O \mathrm{~N}^{\circ} 32,1 / 7 / 1968\right.$, pp. 3-5).

Para 1969, si bien ya no les imputaba las mismas concepciones sobre la lucha armada, el matiz de divergencias político-estratégicas entre ambas fracciones no fue (o no quiso ser) advertido por PO que, cuestionando al PRT-EC de Santucho por la intención de crear el Ejército Revolucionario del Pueblo (ERP), brazo armado del partido, confundió lucha armada y foquismo. En sus palabras: "el partido armado (...) equivale a decir, partido más foco, desconociendo así la construcción del partido marxista" y actuando por fuera de las masas $\left(P O \mathrm{~N}^{\circ} 59,20 / 10 / 1969\right.$, p. 8) ${ }^{28}$.

\section{La Organización Latinoamericana de Solidaridad (OLAS) y las expectativas de PO:}

Desde 1950, la teoria bolchevique de organización revolucionaria se vio enriquecida y confrontada por una oleada de revoluciones en una geografia pronto unificada bajo el concepto de "tercer mundo". En ella, el campesino aparecía como parte de la alianza revolucionaria y la "cuestión armada" tomó un protagonismo significativo. Así, se puso en cuestión la forma de organización que debía adoptar el sujeto revolucionario, sin renegar del leninismo. Luego del triunfo de la revolución cubana, estos enigmas alcanzaron su mayor esplendor a una escala global, en 1966, con la organización de un evento internacional que intentó constituir una coordinadora de luchas revolucionarias, la Organización de Solidaridad de los Pueblos de Asia, África y América Latina (OSPAAL) que había surgido de la I Conferencia Tricontinental. Explorando las producciones a nivel global y latinoamericano sobre la Trincontinental y la OLAS, Stella Grenat ha subrayado que dichos eventos buscaron no sólo proyección internacional sino también disputar la hegemonía de quienes otorgaban un rol central al partido (Grenat, 2020: 287-317).

Por esta razón, en julio de 1967 en La Habana, se llevó a cabo la I Conferencia de la OLAS. El historiador Aldo Marchesi ha examinado el carácter y puesta en marcha de la OLAS para la coordinación y centralización de lucha armada que llevarian adelante las diversas organizaciones revolucionarias en la región conosureña de América Latina. La posición cubana terminó imponiéndose en la I Conferencia ${ }^{29}$. La

\footnotetext{
$28 \mathrm{El}$ resaltado nos pertenece.

29 Dos posiciones emergieron en la misma. La primera y mayoritaria, fue la del anfitrión cubano consistente en que el único camino para promover dicha solidaridad era poner en marcha una estrategia continental de lucha armada. La segunda y minoritaria, fue la de los PP.CC. latinoamericanos más cercanos a los dirigentes soviéticos que proponían una visión moderada, colocando a la lucha armada entre otros dispositivos de lucha, pero ponderando en vistas y consonancia de la "coexistencia pacífica", la lucha sindical y electoral.
}

\section{anuario.}


serie de intervenciones estadounidenses, incluidas Bahía de

Cochinos, la incursión militar en República Dominicana y los diversos golpes de Estado entre 1961-66, eran suficientes para los cubanos. De ahí que, para la OLAS, la única respuesta posible a la "continentalización desde arriba" por medios imperialistas era la "continentalización desde abajo" por medios revolucionarios. La delegación argentina había contado con las presencias del dirigente de la izquierda peronista J. W. Cooke $(\mathrm{MRP})^{30}$, quien habló en representación de la delegación. También participaron G. Elorrio de C y R, J.C. Coral por el PSA, G. Rearte de la J.R.P, J. Vazeilles del MALENA, el secretario general del sindicato de Prensa E. Jozami y miembros del PCA ${ }^{31}$. El PRT, solicitó integrarse y nunca recibió respuesta.

PO no fue ajena a esta situación, el primero en indicarlo fue Coggiola ${ }^{32}$. Utilizando artículos de los periódicos de la organización de 1971 que eran más bien distantes de dicha experiencia, estimó que PO apoyó a la OLAS criticando al foquismo, ya que en sus inicios señaló "la incompatibilidad del castrismo como programa y método, con la IV Internacional, lo que no significaba dejar de reconocer en él, en esos años, una corriente revolucionaria". En 1967-68, continúa, su consigna fue: "por una OLAS de la vanguardia obrera y campesina (Coggiola, p. 209).

Sin embargo, la referencia más sistemática que encontramos en la prensa partidaria de septiembre de 1967, fue saludada con loas y constituyó el mayor intento de acercamiento de $\mathrm{PO}$ al paradigma guevarista solicitando su ingreso. Según se desprende, las posiciones de los dirigentes fueron homogéneas en el apoyo a la iniciativa castrista: "la línea de este artículo fue aprobada por unanimidad en reunión de Dirección Nacional ampliada". Para A. Guillis, uno de sus fundadores, esta no fue para el partido una época caracterizada por tensiones, sino de homogeneidad 33 . Respecto a las características programáticas que presentaba la OLAS, se advierte en la visión de PO, el salto cualitativo en comparación a la III Internacional de cuño stalinista y se denunciaban los intentos soviéticos de bloquear la política de lucha armada. La OLAS era, en la visión de PO, un movimiento con influencias en las masas y la dirección de un Estado Obrero que, por primera vez, "se acercaban en una gran medida a la tesis de la revolución permanente". Por ello, en correspondencia a las resoluciones de la OLAS y al

\footnotetext{
30 Para consultar documentos del Comité Argentino de la OLAS, particularmente de la Acción Revolucionaria Peronista (ARP), ver: https://eltopoblindado.com/

31 Como indica Esteban Campos: "La delegación argentina, era un microcosmos que reproducía (...) la atomización de las izquierdas argentinas". Campos. E. Cristianismo y Revolución. El origen de Montoneros. Buenos Aires, EDHASA, 2016. p.44.

32 Martin Mangiantini también ha abordado a PO y la OLAS, aunque de forma paralela a la corriente morestina, considerando que su lanzamiento produjo una valoración positiva por su carácter antiestalinista y por la negación de la revolución por etapas. Mangiantini. M. Entre tensiones $y$ redefiniciones. El trotskismo argentino ante el paradigma de la revolución cubana en los años sesenta. En Revista Afuera. Estudios de crítica cultural N 17/18. Noviembre de 2016. pp. 8-9.

33 Entrevista telefónica del autor $(26 / 7 / 2020)$.
} 
programa del trotskismo, se arrimaba bastante ya que proclamaba la unidad entre la revolución democrática-antiimperialista y la revolución socialista mediante la dictadura proletaria. En este sentido, PO hacia suya las posiciones que ya había esgrimido Moreno en 1962 (Mangiantini, 2018, p. 45). A su vez, destacan las politicas contrapuestas que habrian significado la dirigencia soviética por un lado, y la dirigencia castrista, por el otro.

[El] carácter histórico esencial consiste en que, por primera vez, (...) un movimiento con influencias en las masas y la dirección de un Estado Obrero se aproximen en una gran medida a la tesis de la revolución permanente, (...) que proclama la unidad entre la revolución democrática-antiimperialista y la revolución socialista mediante la dictadura proletaria, y se aproxima al programa [de] Trotsky para América Latina (...) La conferencia de la OLAS ha generalizado el carácter de la propia revolución cubana, dándose programáticamente carta de ciudadania internacional... [Y creando asi] un organismo revolucionario continental. El significado politico (...) de la OLAS y su programa consiste en representar la única alternativa internacional de carácter revolucionario existente (...). La solidaridad politica de [PO] con este planteo y nuestra lucha, propaganda y agitación a favor de la construcción del partido obrero revolucionario en América Latina, responde por entero a la política de (...), impulsar y profundizar la estrategia revolucionaria (de) la OLAS. [La] OLAS representa una alternativa (revolucionaria que) ha concitado la más fiera represión imperialista, [y] el ataque politico de la burocracia soviética y sus seguidores (...) La OLAS y el estalinismo internacional pro-soviético siguen dos cursos politicos contrapuestos al de la revolución la primera, el de la contrarrevolución el segundo ( $P O N^{\circ} 20$, 8/9/1967, p. 30)34.

Por todo esto, consideraba que no habia "senda pacífica" que valga, sino la insurrección armada como la forma suprema de la lucha revolucionaria de la clase obrera. Por romper con la coexistencia pacífica el castrismo, en la cosmovisión de PO, había asumido la responsabilidad objetiva de "plantarse como partido revolucionario independiente y contrapuesto (...) al stalinismo" (ibídem.). En relación a la concepción foquista asumida por la OLAS y tomando como ejemplo la guerrilla del EGP argentino, PO percibía al foco como "desligado de las masas y que nada tenía que ver, ni teórica ni prácticamente con la guerrilla como forma de la guerra de masas campesinas o de resistencia nacional". Así, "los focos sin ligazón a un movimiento político real de envergadura nacional o nunca existieron o abortaron (Argentina). El M-26J, era mucho antes de la guerrilla una fracción nacional del Partido Ortodoxo, [el] más popular de la pequeño burguesía ciudadana” (ibídem).

A su vez, PO aseveraba que América Latina se hallaba ante un repliegue del movimiento de masas. En ese marco, ¿qué era el foquismo? "un intento de llenar el vacío dejado por ese retroceso sin acometer la tarea de reorganizar a la vanguardia de las capas oprimidas (....), suplantándola por la acción voluntarista de un grupo

$34 \mathrm{El}$ destacado nos pertenece. 
pequeño burgués armado". En tal sentido, PO sostenía que "combatía al foquismo" porque en la práctica constituiría, "un programa de acción para el estudiante que concibe su destino revolucionario desgajándose de su clase pero sin entroncar con la lucha proletaria" ( $P O \mathrm{~N}^{\circ} 20$, pp. 45-47). En diciembre de 1967, con el Che ejecutado, se refieren al foco como el desarrollo unilateral de la lucha guerrillera y al margen de la agitación revolucionaria y organización de masas. Con todo, había "que alinearse internacionalmente con la alternativa revolucionaria de la OLAS y (...) clasistamente por la reconstrucción del partido obrero revolucionario, que es el que llevara esa alternativa a la victoria ( $P O \mathrm{~N}^{\circ} 23,14 / 12 / 67$, pp. 1-4).

A fines de 1967, la dirección de PO se autocriticó el hecho de haber retrasado su ingreso en la OLAS. Por eso, inició gestiones para incorporarse, con vistas a realizar un congreso a mitad de 1968 en donde se discutiera la politica del organismo continental y se agitaran sus planteos en talleres, fábricas, universidades, etc. Bajo el VIII Congreso de la FUA, liderado por la Federación Juvenil Comunista en discordia con la política reformista que aplicaba su propio partido ${ }^{35}$, PO colocó a través de su organización estudiantil TESR ${ }^{36}$, el planteo de apoyo a la OLAS donde no admitía puntos grises, sintetizado en polos tales como: coexistencia pacífica o lucha revolucionaria, socialismo en un solo país o revolución continental y revolución por etapas o revolución socialista. Allí, se recriminaba que la dirección estudiantil viera a la OLAS como un organismo más de solidaridad, según PO "algo así como la $\mathrm{LADH}$, quitándole toda significación a su programa y a su política" ( $P O$ $\mathrm{N}^{\circ}$ 24, 4/1/1968, pp. 30-31). En este sentido, se pretendía que la FUA y su dirección dieran un apoyo programático más explícito.

Tras el $9^{\circ}$ aniversario de la revolución cubana, PO destacó que el nacimiento de la OLAS fue una muestra de que la revolución cubana había dado lugar a una dirección revolucionaria y socialista independiente de los aparatos burocráticos que dominan en el terreno internacional. Por consiguiente, había que incorporarse a la OLAS para impulsar este curso y cristalizarlo en cada país construyendo partidos obreros revolucionarios (ibídem). Con una visión que creemos impresionista - dado que la premisa guevarista promovía una unidad de las luchas por sobre las diferencias politicas-, que mostraba más los anhelos de la propia PO antes que de la OLAS, se afirmaba que "la OLAS combatía a muerte a los reformistas y claudicantes que pretendian engañar a los obreros y campesinos de América Latina en las posibilidades "progresistas" de los capitalistas nacionales" (ibídem.) Como se ve, a pesar de sus críticas al foco, PO no ponía en cuestión este aspecto a la hora de defender a la OLAS, sino el acercamiento castrista al stalinismo.

\footnotetext{
35 Dichas tensiones darían lugar, posteriormente, a la conformación de dos nuevos partidos maoístas: el PCR y VR.

36 Organización estudiantil universitaria y secundaria de PO.
} 
Definitivamente, PO nunca ingresaría a la OLAS. Puede pensarse que a mediados de 1968 y principios de 1969, el mayor alineamiento de Castro a la dirigencia soviética -expresada en particular por el apoyo cubano a la invasión a Checoslovaquia - haya ocasionado en PO un replanteamiento sobre si la dirigencia castrista seguía abrigando una "alternativa revolucionaria y socialista" acaudillada en la OLAS. En 1969 revería su posición en relación a las expectativas positivas del bienio 1967-1968, ya que el intento más importante de romper internacionalmente con la hegemonía de la burocracia stalinista fue la OLAS, actualmente "ha entrado rápidamente en el estancamiento", sostuvo PO. A la luz de los fracasos de los grupos armados en el continente y en especial la experiencia boliviana, políticamente PO se apartará aún más. En este cuadro apuntó que la OLAS había nacido como una reacción a "la coraza que imponían las direcciones nacionalistas y comunistas” en América Latina, pero gestándose no como una alternativa para construir partidos obreros revolucionarios, sino para apoyar e incrementar las organizaciones "puramente foquistas". La OLAS habria planteado "la lucha armada contra el imperialismo" por fuera de la experiencia y actividad de la vanguardia obrera y campesina. En este sentido,

Mal podría en estas condiciones jugar el rol de partido internacional. (...) sólo este rol le estaba abierto a la OLAS; habiéndolo rehusado por su concepción foquista, entró en el más completo aislamiento. Reclamamos (...) a menos de dos meses de la segunda conferencia de la OLAS (...) un examen autocritico de toda la actividad (...) (Archivo CPM, Mesa B, Factor Gremial, Carpeta Actividad panfletaria, Folios 56-57; $\left.P O N^{\circ} 50,21 / 4 / 1969\right)$.

Podría decirse que el mayor quiebre y alejamiento en las posiciones de PO se daría con las jornadas del Cordobazo, donde el partido apostaría por una radicalización de la lucha urbana obrero-estudiantil y a una mayor inserción en el movimiento obrero, en línea con ese curso insurrecionalista. El ingreso a los años '70, expresaría una persistente toma de distancia respecto al castrismo y a las exceptivas favorables con las que se expidió en sus años formativos.

\section{Consideraciones finales}

El presente artículo intentó presentar las posiciones de una joven y pequeña organización del llamado campo de la "izquierda no armada" ante las guerrillas latinoamericanas, a partir de los casos de Guatemala y Bolivia y también sus concepciones sobre la OLAS. A partir de los mismos, hemos podido constatar que PO no rehuyó del debate sobre el foquismo, táctica hegemónica en la izquierda latinoamericana de los años ‘60. En el caso guatemalteco, su apoyo al MR-13 estuvo asociado a la ligazón de éste con el trotskismo posadista, la adopción de un programa socialista revolucionario y el alejamiento del PGT, que PO veía ya

\section{anuario.}


"burocratizado". En el caso boliviano, se hizo eco y asimiló algunas

críticas del lorismo al guerrillerismo en Ñancahuazú. En especial aquellas que impelían a los guerrilleros a unificarse con las luchas de los mineros en las ciudades y que criticaban que el foco acumularía la fuerza social necesaria para hacer la revolución.

Por otra parte, la creación de la OLAS se comportó como el suceso más sobresaliente en la internacionalización de la estrategia foquista de cuño guevarista $\mathrm{y}$, en el intento de acercamiento de PO a dicho paradigma, siempre condicionado a un replanteamiento político estratégico, organizativo y de alianzas. Su respaldo e incluso militancia a favor de la OLAS, estuvieron siempre condicionadas a que dicho organismo se despegara (e incluso rompiera) del stalinismo y que asumiera una perspectiva en la construcción de partidos obreros latinoamericanos que se insertaran en el movimiento proletario.

Al haber leído al foquismo a través de Debray, se crearon imágenes distorsionadas sobre la lucha armada, llegando incluso a confundir todas las formas de acción armada con el foquismo - que fue solo una táctica- Hemos visto que al haber estado desprovisto de una experiencia teórica y militante previa en el trotskismo, esa falta de experiencia intentó ser subsanada con la asimilación de las críticas de otras corrientes del trotskismo conosureño al foquismo - como el lorismo y el morenismo-. El mayor alineamiento del castrismo con Moscú, más la derrota del Che Guevara en Bolivia y las jornadas insurreccionalistas de la clase obrera argentina en el Cordobazo, empujaron a PO a distanciarse de la OLAS - y por lo tanto del guevarismo-. Queda abierta la cuestión de cómo fue atendido el tratamiento del foquismo a partir de los años 70 , tanto a nivel latinoamericano, como local. Nuestra impresión es que no varió sustancialmente de las caracterizaciones que hemos puesto de relieve. Así, este artículo intentó contribuir a la reconstrucción del campo de "la izquierda no armada" y del trotskismo vernáculo en particular.

\section{Bibliografia}

Campos, E. (2016). Cristianismo y Revolución. El origen de Montoneros. Buenos Aires: EDHASA.

Coggiola, O. (2006). Historia del Trotskismo en Argentina y América Latina. Buenos Aires: Ed. ryr. 
Debray, R. (1967). ¿Revolución en la revolución? Chile: Centro de Estudios Miguel Enriquez (CEME).

Debray, R. (1964-1965). EL CASTRISMO: La gran marcha de América Latina. Pasado y Presente, Revista de ideología y cultura, N 7-8, pp. 122-158.

Díaz, J. (2017). El Movimiento Izquierda Revolucionaria (Praxis) y la construcción del Partido Obrero (1955-1960). Izquierdas, No 36, pp. 253-277.

Díaz, J. (2019). El trotskismo y el debate de la lucha armada: los casos de Baluarte y Politica Obrera. (En prensa).

Grenat, S. (2020). El principe armado. El estudio de la Tricontinental y la OLAS en América Latina. Una tarea pendiente. Revista Intellectus, Año XIX, $\mathrm{N}^{\circ}$ 1, pp. 287-317.

Guevara. E. (1967). Mensaje del Che Guevara a los pueblos del mundo a través de la Tricontinental. Chile: Centro de Estudios Miguel Enriquez (CEME).

Guevara. E. (2015). Pasajes de la guerra revolucionaria. La Habana, Cuba: Editorial de Ciencias Sociales.

Kohan, N. (2005). Ernesto Che Guevara. El sujeto y el poder. Buenos Aires: Edit. Nuestra América.

Lora, G. (2011). Revalorización del método de guerrillas (1968). En Revolución y foquismo. Balance de la discusión sobre la desviación "guerrillerista". Buenos Aires: Ed. RyR.

Malaspina, L. (2017). El impacto de la Revolución Cubana en el MIR-Praxis y su estela en el núcleo fundador de Política Obrera. Presentado en XVI Jornadas Interescuelas/Departamentos de Historia.

Mangiantini, M. (2014). El trotskismo y el debate en torno a la lucha armada. Moreno, Santucho y la ruptura del PRT. Bueno Aires: Editorial Colección Controversias.

Mangiantini, M. (2016). Entre tensiones y redefiniciones. El trotskismo argentino ante el paradigma de la revolución cubana en los años sesenta. Afuera. Estudios de critica cultural $\mathrm{N}^{\circ} 17 / 18$.

Mangiantini, M. (2018). Itinerarios militantes. Del Partido Revolucionario de los Trabajadores al Partido Socialista de los Trabajadores (1965-1976). Buenos Aires: Imago Mundi. 
Marchesi, A. (2019). Hacer la revolución. Guerrillas Latinoamericanas. De los años sesenta a la caída del Muro. Buenos Aires: Siglo XXI.

Pereyra, D. (2011). Del Moncada a Chiapas. Historia de la lucha armada en América Latina. Buenos Aires: Ed. RyR.

Petra, A. (2017). Intelectuales y cultura comunista. Itinerarios, problemas y debates en la Argentina de posguerra. Buenos Aires: FCE.

Rath, C. (2015). El MIR (Praxis) y Silvio Frodizi en la historia del movimiento obrero argentino. Revista En defensa del marxismo $\mathrm{N}^{\circ} 45$.

Rojo, A. (2012). Los orígenes del trotskismo argentino: de los años 30 al surgimiento del peronismo. Elaboraciones teórico-politicas y vínculos con la clase obrera. Archivos de historia del movimiento obrero y la izquierda, $\mathrm{N}^{\circ} 1$.

Rot, G. (2003-2004). Notas para una historia de la lucha armada en la Argentina. Las Fuerzas Argentinas de Liberación. Politicas de la Memoria, n. 4, pp. $137-160$.

Rot, G. (2009). El Ejército Guerrillero del Pueblo y los orígenes perdidos de la guerrilla Argentina. Buenos Aires: Waldhutter.

Samuel, A. (2005). Silvio Frondizi y el surgimiento de la nueva izquierda. CEMA Working Papers: Serie Documentos de Trabajo $\mathrm{N}^{\circ} 313$.

Sándor, J. (2016). El trotskismo boliviano. Revolución permanente en el Altiplano. Bolivia: Ed. Plural.

Tarcus, H. (1996). El marxismo olvidado en la Argentina: Silvio Frondizi y Milciades Peña. Buenos Aires: Ediciones El cielo por asalto.

\section{Prensa}

“Editorial”. En PO N 1. Año I. Marzo de 1964.

"Foco insurreccional o partido revolucionario". En PO N 1 . Año I. Marzo de 1964.

"La real importancia de la guerrilla guatemalteca". En PO $\mathrm{N}^{\circ} 3$, suplemento periódico, agosto-septiembre de 1965. (9-8-1965). 
"Declaración del M.R. 13 de noviembre Guatemalteco al cumplir su Quinto Aniversario". En PO N 3, suplemento periódico, agosto-septiembre de 1965. (9-8-1965).

"El POR boliviano y la guerrilla". En PO N 18. Boletín Trimestral. Año II. (197-1967).

"La conferencia de la OLAS". En PO N²0. Boletín Trimestral Año II. (8-91967)

“En defensa de la OLAS". En PO N²3. Boletín Trimestral. Año II-. (14-12-67).

"El 8 congreso de la FUA". En PO N²3. Boletín Trimestral. Año II-. (14-12$67)$.

“La guerrilla boliviana”. En PO N²3. Boletín Trimestral. Año II-. (14-12-67).

"Viva el $9^{\circ}$ aniversario de la revolución cubana". En PO $\mathrm{N}^{\circ}$ 24. Boletín Trimestral. Año III. (4-1-1968).

"El PRT vira hacia un foquismo primitivo (Marcelo Martín [Foix] 2-1-68)". En PO N² 24. Boletín Trimestral. Año III. (4-1-1968).

"Las FAR de Guatemala rompen con el Partido Comunista". En PO N²6, Boletín trimestral, Año II. (15-2-1968).

"Guatemala: ruptura de las F.A.R. y el Partido Comunista". En PO N²7, Boletín trimestral, Año II. (7-3-1968).

"La guerrilla guatemalteca rompe con el Partido Comunista". En PO N²8, Boletin Quincenal, Año II. (25-3-1968).

"Alba: positiva lección para reformistas y "putchistas". En PO N²9, Año II, Boletín Quincenal. (15-4-1968).

"Seguir el ejemplo revolucionario francés" [Editorial et al]. En PO $\mathrm{N}^{\circ} 31$, Boletín Quincenal, Año II. (10-6-1968).

"El Combatiente" se pasó. Apoya el golpe Alsogaray". En PO N 32, Año II. (17-1968).

"Bolivia. Por la lucha armada. Por la construcción del partido revolucionario". En PO N 34. Boletín Quincenal. Año III. (5-8-1968).

"En el primer aniversario del asesinato del Che". En PO $\mathrm{N}^{\circ} 37$. Boletín quincenal. Año III. (30-9-1968). 
"1 ${ }^{\circ}$ de mayo apostar más que nunca al derrocamiento del capitalismo mundial y de la burocracia contrarrevolucionaria". En PO $\mathrm{N}^{\circ}$ 50.Boletín Quincenal. Año III. (21-4-1969)

"Che Guevara. 19678 de octubre 1969. Hasta la victoria siempre". En PO N 59. Año IV. (20-10-1969).

\section{$\underline{\text { Otros documentos }}$}

Volante de PO (24-4-1969). Archivo CPM, Mesa B, Factor Gremial, Carpeta "Actividad panfletaria", Legajo caratulado "panfleto Política Obrera". Folios 5657 "Bittel” (1979). En Archivo de la Comisión Provincial por la Memoria (Ex DIPBA).

Recibido: 4 de enero de 2021

Aceptado: 16 de febrero de 2021

Versión Final: 28 de abril de 2021 